Research Article

\title{
Recent Progress in Polymer-Based Building Materials
}

\author{
Jingjing Shen $\mathbb{D}^{1},{ }^{1}$ Jianwei Liang, ${ }^{2}$ Xinfeng Lin, ${ }^{1}$ Hongjian Lin, ${ }^{1}$ Jing Yu, ${ }^{1}$ \\ and Zhaogang Yang $\mathbb{D}^{3}$ \\ ${ }^{1}$ School of Civil Engineering and Architecture, Taizhou University, Taizhou, Zhejiang 318000, China \\ ${ }^{2}$ Taizhou Urban and Rural Planning Design Institute, Taizhou, Zhejiang 318000, China \\ ${ }^{3}$ Department of Radiation Oncology, University of Texas Southwestern Medical Center, Dallas, TX 75390, USA
}

Correspondence should be addressed to Jinging Shen; shenjingjing@tzc.edu.cn

Received 29 September 2020; Revised 6 November 2020; Accepted 19 November 2020; Published 2 December 2020

Academic Editor: Wen Shyang Chow

Copyright $\odot 2020$ Jingjing Shen et al. This is an open access article distributed under the Creative Commons Attribution License, which permits unrestricted use, distribution, and reproduction in any medium, provided the original work is properly cited.

With the development of human society, the requirements for building materials are becoming higher. The development of polymer materials and their application in the field of architecture have greatly enhanced and broadened the functions of building materials. With the development of material science and technology, many functional materials have been developed. Polymer materials have many excellent properties compared with inorganic materials, and they can also be improved to enhance functional properties by blending or adding various additives (such as flame retardants, antistatic agents, and antioxidants). In this paper, polymer-based building materials are introduced with three classes according to the applications, that is, substrates, coatings, and binders, and their recent signs of progress in the preparations and applications are carefully demonstrated.

\section{Introduction}

The building industry plays an important role in the development of human history. The development of the building industry is inseparable from various building materials. Building materials can be divided into structural materials, decorative materials, and some special materials. Structural materials include wood, bamboo, stone, cement, concrete, metal, brick, ceramics, glass, engineering plastics, and composite materials; decorative materials include various coatings, paints, plating, veneering, ceramic tiles of various colors, and glass with special effects; special materials refer to waterproof, moisture-proof, anticorrosion, fire-retardant, sound insulation, heat insulation, and sealing.

With the development of material science and technology, polymer materials exhibit application potentials in the building industry attributed to their excellent properties compared with inorganic materials, such as waterproof, anticorrosion, wear resistance, antiseismic, lightweight, good strength, sound insulation, heat insulation, good electrical insulation, and bright colors. Due to their superior properties, polymer mate- rials have been widely used in the building industry, such as the insulation layer of the water supply pipe, drainage pipe, wire and cable, and wall insulation material.

Commonly used building polymers include polyethylene (PE), polyvinyl chloride (PVC), polymethyl methacrylate (PMMA), polyester resin (PR), polystyrene (PS), polypropylene (PP), phenolic resin (PF), and organic silicon resin (OSR). By adding functional additives into these polymers or adding these polymers into traditional building materials, such as concrete and mortar, the polymer-based building materials have great potential in construction engineering. In this paper, polymer-based building materials are introduced with three classes according to the applications, that is, substrates, coatings, and binders, and their recent signs of progress in the preparations and applications are carefully demonstrated.

\section{Polymer Substrates}

A polymer is a kind of material based on natural or synthetic macromolecule compounds, which is plasticized and formed under high temperature and pressure with appropriate fillers 
and additives, and keeps the shape of products unchanged under normal temperature and pressure [1-3]. Generally, a polymer is composed of synthetic resin, filler, plasticizer, curing agent, colorant, stabilizer, etc. $[4,5]$. The addition of some functional additives can make plastics have some better performances and broader applications. For example, the addition of foaming agents can process foam plastics and the addition of fire retardants can process flame-retardant plastics. They have a wide range of applications, and this section focuses on polymer-based substrate materials including concrete, prefabricated elements, and strengthening connectors [6-9].

2.1. Polymer Concrete. Polymer concrete is a relatively novel high-quality material. Compared with cement concrete, it has many advantages such as good mechanical strength, short curing period, high adhesion, wear resistance, weather resistance, waterproof, and high insulation performance [10-14]. Due to these properties, polymer concrete has widespread construction applications compared with conventional cement concrete, such as prefabricated walls; hydraulic structures including dikes, reservoirs, and piers; road surfaces and decks; and underground constructions [15-17]. Many types of polymers can be used in polymer concrete including polyester, furan, vinyl, rubber, phenol, epoxy, and acrylic resins [18-20].

Polyester polymer concrete (PPC) has been widely used in constructions due to its advantages of fast setting and hardening time, high mechanical strength, low permeability, and good chemical resistance [21-25]. Seco et al. [26] prepared PPC building products and characterized their durability based on the damage and mechanical strength losses after freezing and thawing. Results showed that no surface damage existed in PPC building products after 25 cycles of freezing followed by thawing in water according to European Standard EN 14617-5.

Epoxy resin-based polymer concrete with good strength has excellent properties, but its cost is very high, which restricts its wide applications $[27,28]$. Compared with epoxy, epoxy-urethane acryl $[29,30]$ is $100 \%$ reactive and does not require solvent evaporation or special equipment for the recovery of solvent, and thus, environmental pollution and impact on the workers are minimized. Additionally, it even has some enhanced properties such as wear resistance, flexibility, elasticity, adsorption capacity to impact, and resistance to the environment. Agavriloaie et al. [31] developed a new polymer concrete based on epoxy-urethane acryl and aggregates and characterized its property through mechanical and thermophysical tests. The epoxy-urethane acryl concrete exhibited comparable mechanical characteristics, including compressive strength, flexural strength, and elasticity modulus, to the polyester resin concrete.

In addition to common polymers, biopolymers have also been used to prepare polymer concrete. Biopolymers are polymers produced by living organisms, which are usually cheap, biodegradable, and renewable. These advantages make them an attractive material for food and nonfood applications. Kulshreshtha et al. [32] prepared a novel biobased concrete by mixing sand, water, and corn starch and then heating the mixture they formed (Figure 1). In the presence of water, the corn starch after being heated will form a gel, which can harden and combine with the sand grains. The strength of the corn-based concrete (CoRncrete) is very sensitive to water concentration and influenced by the sand size, heating method, and time.

\subsection{Prefabricated Polymer Elements. The construction indus-} try is transforming into prefabrication or modularization, which has the advantages of fast construction, high-quality control, less waste, and construction interruption [33, 34]. To realize this transformation, the prefabricated building or elements are required to possess a high strength-to-weight ratio, ease of application, and lightweight. Fiber-reinforced polymers (FRPs) obtain all these properties and thus have been increasingly used in the building industry. Attributed to the excellent properties, the introduction of FRPs into prefabricated buildings is beneficial to both the structural and nonstructural components, and they have the potential to revolutionize the prefabrication building industry and to provide adequate housing for the booming population. The lightweight nature of FRP eliminates the transportation and lifting issue in prefabricated systems, as it can produce lightweight nonstructural elements such as partitions, infill walls, parapets, curtain walls, and facade systems [35-37]. These FRPs also have the ability to produce excellent weather resistance, high durability, adaptable aesthetic appeals, and cost-effective manufacturing processes. These abilities increase the attraction of architectures and designers to use the FRPs in building facades.

A typical structure of FRPs is shown in Figure 2(a) [38]. FRPs have been used to replace the traditional construction materials (i.e., steel-reinforced concrete and timber) in modern buildings. FRPs also have the potential to strengthen the existing structural elements and reduce the amount of reinforcement and cementitious materials in concrete [39-42]. In recent years, some structural (i.e., walls, beams, columns, and slabs) and nonstructural (i.e., facades and curtain walls) elements in the buildings have been fabricated with FRPs [43-45]. Figure 2(b) shows some examples in which FRPs are used to construct facades of new buildings.

When used in structural applications, the strength of FRPs will provide the load-bearing capacity of the structures $[46,47]$. The high strength-to-weight ratio, good insulation character, and excellent electrochemical corrosion resistance of FRPs lead them to be an alternative to the traditional steel reinforcement concrete, especially in coastal regions $[48,49]$. However, the mechanical properties of FRPs including the elastic modulus and strength decline with the environmental temperatures, which would lead to unusable deflection and loss of tensile strength [50-56]. The variation of the strength and elastic modulus of FRPs ranges from $20 \%$ to $100 \%$, which is associated with the type of fiber, orientation, volume fraction of fibers, type of resin, and fillers [52].

In addition, the thermal conductivity of FRPs is usually lower than that of the traditional construction materials (i.e., timber and concrete) [57]. The testing by Scott and Beck [58] showed that the thermal conductivity of FRP varied linearly from $0.77 \mathrm{~W} / \mathrm{mK}$ to $0.85 \mathrm{~W} / \mathrm{mK}$. This thermal conductivity variation is dependent on the fiber type, resin type, fiber volume fraction, fiber architecture, fillers, etc. Besides, FRPs have 

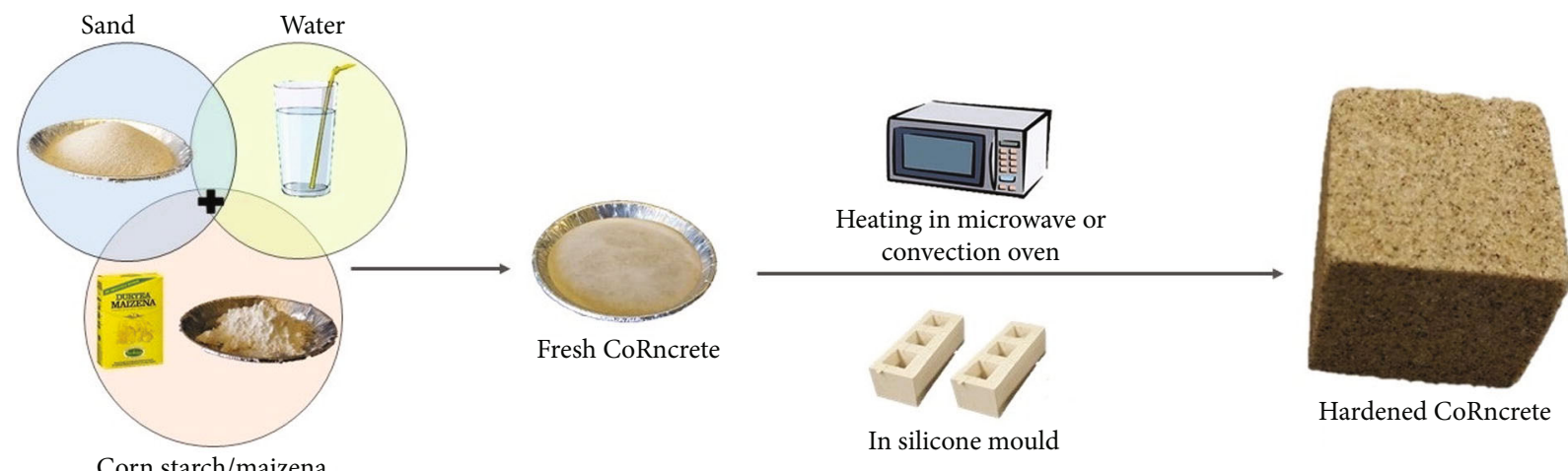

FIGURE 1: Preparation of hardened CoRncrete by heating a mixture of sand, water, and corn starch in a microwave or a convection oven [32].

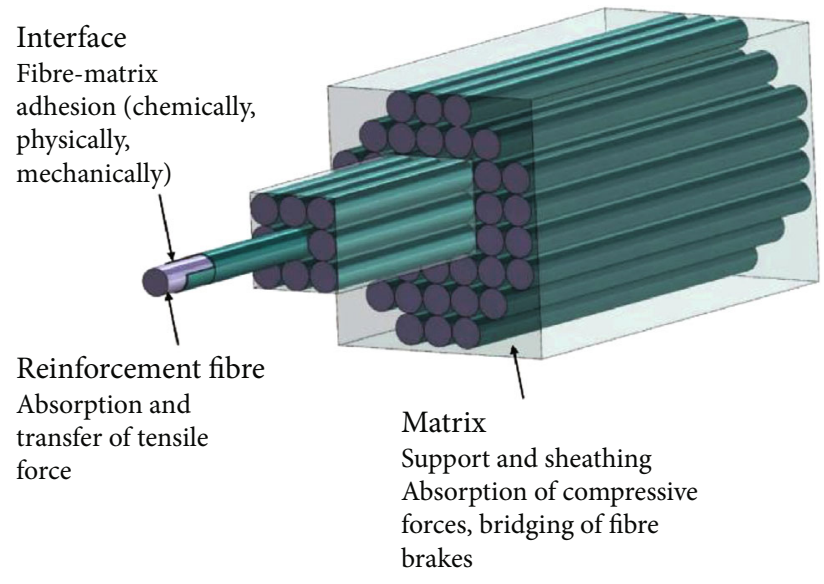

(a)

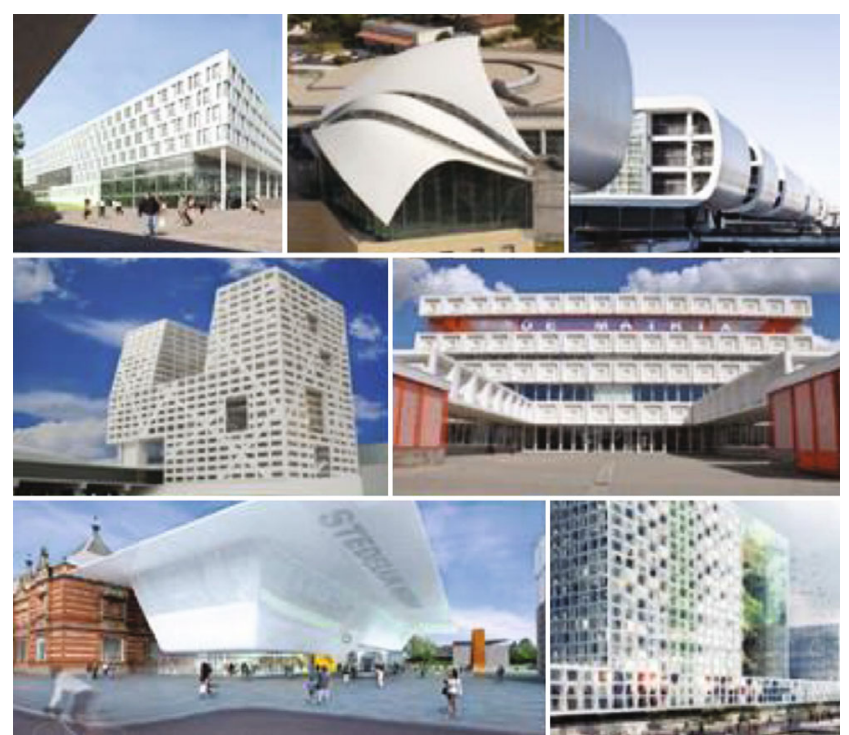

(b)

Figure 2: Typical structure of FRPs (a) and examples of FRP building facades (b) [38].

pyrolysis behavior under fire [59]. However, there is limited conclusive evidence available on the total behavior of FRP structural elements under fire $[60,61]$. Therefore, the fire retardant is one of the significant research topics for the applications of FRPs in buildings.

Lightweight FRPs with good thermal insulation in nonstructural elements (i.e., facade) will reduce the heat gain or loss to the surrounding environment. The facade is often a non-load-bearing element and designed to resist the movement of the building structure. However, FRP facade systems can potentially contribute to the fire spread of buildings and become the most critical element in the event of fire, if the facade system is not well designed or understood. Another factor threatening the capability of the FRP facade system is wind-driven fire; it might reduce the fire performance as it can increase the ignition, fire spread, flammability, and heat release risks [62]. The heat release of the FRP facade from a fire can be significant and lead to a flashover or consequent building collapse $[63,64]$. Flashover action can be prevented by using flame retardants such as organoclay in the FRP system; for example, 5\% organoclay in glass fiber-reinforced polymer (GFRP) can help to minimize the flashover and also horizontal flame spread [34].

The heat released from GFRP composite facade panels has also been studied, and the heat release risk of the GFRP composite facade is significantly less than that of the traditional polymer facade system. A study by Nguyen et al. [35] on the GFRP facade system showed that the heat release of the GFRP facade system meets the fire safety requirements according to EN13501, while it does not meet the required smoke-related safety requirements. Further, Nguyen et al. [35] suggested that the heat release and smoke released from GFRPs can be improved with flame retardants such as aluminum trihydride. The release of smoke and toxic gas from FRPs in a fire is another concern when being used for the exterior facade. Depending on FRPs and other components in the facade such as polypropylene wool and combustible sarking, dense black smoke of carbon monoxide and other 
toxic gases such as hydrogen cyanide can emit directly to the surroundings. This smoke release can create a toxicity hazard and corrosive environment $[65,66]$.

2.3. Strengthening Elements. Polymers or FRPs also have the application for strengthening or repairing masonry constructions, especially for ancient buildings. Significant research campaigns were carried out in the last decade to evaluating the effectiveness of strengthening techniques based on monodirectional FRP sheets glued on the surfaces of the walls by means of epoxy resin. The technique permitted to obtain a significant increase in shear capacity of existing masonry with negligible increases of structural mass, but serious problems of delamination occur that need to be solved through mechanical anchorages. Gattesco et al. [67] prepared a glass fiber-reinforced polymer (GFRP) mesh by coating a thermohardening resin onto long fibers of glass and then twisting the resin-impregnated transversal fibers across the longitudinal wires to form the mesh. The GFRP mesh was used to reinforce the masonry samples strengthened with a mortar coating covered on both surfaces of the wall. Testing experiments showed that the GFRP mesh possesses an excellent strengthening effect.

Tomazevic et al. [68] strengthened a series of stone masonry walls with different types of polymer coatings. One polymer coating consists of a GFRP mesh as reinforcement and a fiber-reinforced cementitious mortar 15-20 mm thick as a matrix. The other polymer coating consists of GFRP fabric strips $30 \mathrm{~cm}$ wide as reinforcement and epoxy resin as a matrix. Testing experiments were carried out in which polymer coatings were applied on both sides of the walls and anchored to the masonry in the corner, and there was no significant difference in the efficiency between different types of coatings.

Gattesco and Boem [69] demonstrated a technique in which a mortar coating with GFRP meshes embedded is used onto the masonry surface for strengthening. The GFRP mesh technique (Figure 3 ) includes applying a thin layer of scratch coating on the surface of a masonry wall or vault, making some holes (diameter $25 \mathrm{~mm}$ ), applying the GFRP mesh, inserting an L-shaped GFRP connector into the hole, and injecting thixotropic cementitious mortar. Further, an extra GFRP mesh device is utilized for improving the linking of the connector to the mortar surface. Moreover, a mortar coating which is around $3 \mathrm{~cm}$ thick is used.

2.4. Others. In addition to the concrete, prefabricated structural elements, and strengthening elements, polymers have a wide range of other applications such as plastic wallpapers, decorative panels, plastic floors, plastic doors and windows, pipeline sheaths, plastic films, sealants, pipes, and sanitary facilities.

Polymethyl methacrylate (PMMA) is an optically transparent thermoplastic with excellent weather and scratch resistance. Nowadays, it is commonly applied in the construction industry as a replacement of inorganic glass attributed to its high impact strength, lightweight, and crush resistance [70]. The tensile and impact strength of PMMA is 7-18 times higher than that of ordinary glass, and its transmit- tance reaches $92 \%$, which is also higher than that of glass. Figure 4 shows some typical applications of PMMA in construction and buildings including tunnels, sheds, and street lamps [71].

Ethylene tetrafluoroethylene (ETFE) foils are widely used in some environmental and aesthetical buildings, including greenhouses, stadiums, and airport terminals, because ETFE structures exhibit outstanding structural, light, thermal, and energetic behavior compared with glass structures [72]. In 1981, ETFE foils were firstly introduced to build roofs in Burgers' Zoo of the Netherlands. After that, ETFE foils have obtained tremendous attention in construction engineering. Figure 5 shows two typical buildings with ETFE foils including the National Aquatics Center and Changzhou Flora Expo in China [73].

\section{Polymer Coatings}

Building coatings are used for coating on the surface of building products and forming a continuous film, so as to protect the building products, beautify the environment, and provide special functions. They can be used in many parts of buildings, such as exterior walls, interior walls, floors, ceilings, and roofs. Common building coatings include fire-retardant coatings, waterproof coatings, heat insulation coatings, selfhealing coatings, sterilization coatings, icephobic coatings, and anticorrosive coatings.

3.1. Fire-Retardant Coatings. Fire is a serious threat to humans and the buildings they construct. Many new methods and materials have been developed to prevent the impact of fire on them. At present, more and more attention has been paid to the fire-retardant design of buildings. Passive fire retardancy of high-rise buildings is a serious problem because of the use of load-bearing steel structures and has attracted more and more attention after the collapse of the World Trade Center. Traditional passive fire-retardant materials include concrete cover, gypsum board, and cement-based coating. These materials have poor aesthetics.

Fire-retardant coatings have been developed to prevent fire threats to people, which can simultaneously provide good aesthetics. They can enhance the fire resistance of buildings and slow down the spread of flame, thereby providing time for extinguishing the fire. Common fire-retardant coatings could be divided into nonintumescent coatings and intumescent coatings. The nonintumescent coatings usually contain polymer synthetic resin doped with incombustible substances, such as halogen, phosphorus, and nitrogen, as the main membrane materials. The intumescent coatings usually consist of the incombustible resin, flame retardant, carbon-forming agent, and foaming agent.

3.1.1. Nonintumescent Fire-Retardant Coatings. Shao et al. [74] successfully prepared an effective fire-retardant coating using phenolic epoxy resin (PER), ammonium polyphosphate (APP), and tannic acid-functionalized graphene (TGE) and tested its fire retardancy and heat insulation by coating it on the surface of the EPS foam plate (EPS/ATG). This fire-retardant coating is equivalent to the shielding of 


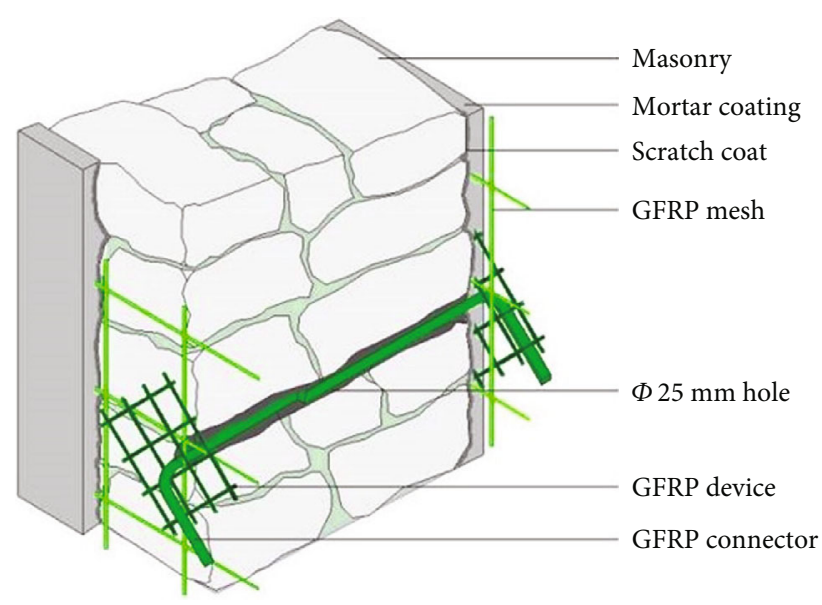

(a)

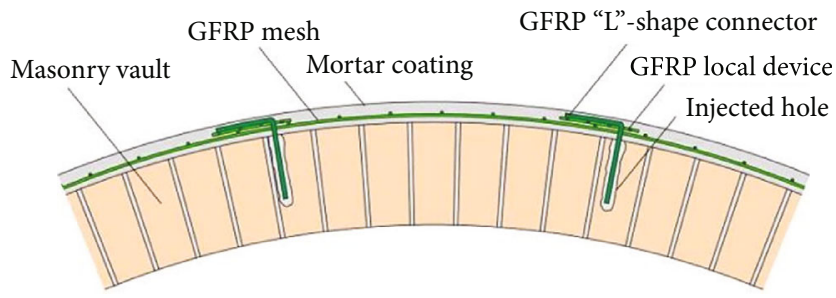

(b)

FIGURE 3: Schematic of the GFRP mortar coating system used (a) on two sides of a masonry wall or (b) at a vault extrados [69].

the polystyrene foam plate. The PER/APP/TGE fireretardant coating prepared at the ratio of $20: 20: 0.65$ exhibits excellent fire retardancy. The experimental results of the cone calorimeter indicated that the peak heat release rate of the EPS/ATG20 foam plate was reduced by $53.8 \%$ and the ignition time was 75.7 times longer compared with the EPS foam plate. The thermal conductivity of the EPS/ATG20 foam plate enhanced to $0.053 \mathrm{~W} / \mathrm{mK}, 0.048 \mathrm{~W} / \mathrm{mK}$ higher than that of the EPS foam plate. The PER/APP/TGE coating endowed the EPS/ATG foam plate not only with excellent fire retardancy but also with good heat insulation.

Melamine and melamine resins are a series of highperformance fire retardants for polymer building materials because of blowing within intumescent layers, char forming, and release of ammonia and nitrogen. Cured melamine systems are utilized in heat-sensitive objects, such as furniture, window frames, and sills. Farag et al. [75] used differently cured methylated poly (melamine-co-formaldehyde) (cmPMF) resins as fire-retardant coverings for poly(styrene) (PS) and poly(ethylene) (PE) building materials.

This type of polymer coatings, which are made by dip coating, should be several tenths of a micron thick to afford adequate fire retardancy. To ensure adequate adhesion between the thick coating and the polyolefin matrix, and in the case of high temperatures during fire exposure, the plasma polymer layer with hundreds of nanometers thick was first coated on the polymer substrate. The thin plasma polymer layer was prepared by low-pressure plasma polymerization of allyl alcohol. The thick coating of the melamine prepolymer and curing melamine resin with the thin plasma polymer layer as an adhesion promoter led to positive effects on fire retardancy of polystyrene and polyethylene.

3.1.2. Intumescent Fire-Retardant Coatings. The intumescent fire-retardant coating is a new type of passive fire-retardant coating, which is usually used in the form of film. It expands many times than the original thickness to form insulating carbon, which provides a barrier between the fire and the structure. It can prevent the temperature of steel parts from increasing to the critical point and help to maintain the integ- rity of the structure in case of fire. Because of the properties of beauty, flexibility, fast use, easy inspection, and maintenance, the intumescent fire-retardant coating is the first choice for architects and designers to passive fire protection of loadbearing steel frame structure.

The organic intumescent coating has a good-quality finish and could be a topcoat if exposed outdoor. However, it forms a fluffy char sometimes after exposure to fire, which may fall off at high wind speed. In general, the organic intumescent coating is based on an acid catalyst, a char former, and a blowing agent in solvent-borne or waterborne binders. Compared with alkali silicate coatings, this kind of coatings has better weather stability and water resistance. People favor passive fire protection of steel frames because they provide finishes that do not affect the appearance of exposed steel structures as cement coatings do. Nowadays, the organic intumescent coating has been widely used in modern airports, skyscrapers, sport or shopping centers, hotels, and other places, enabling architects to use steel creating and designing elements [76, 77].

$\mathrm{Xu}$ et al. [78] prepared three intumescent fire-retardant coatings, such as acrylic resin/expandable graphite (EG), alkyd resin/EG, and epoxy resin/EG, and tested their fireretardant property by coating them on shape-stabilized phase change materials. Results showed that all the three fireretardant coatings can form thick porous char layers when exposed to fire and thus delay the evaporation of paraffin, trap the generated combustibles, hinder the conduction of heat into the matrix, and prevent the diffusion of oxygen.

3.2. Waterproof Coatings. Waterproofing is a common and serious issue to ensure the normal use of building elements, such as concrete bridge decks or roofs [79]. Orthotropic bituminous membranes modified with the styrene-butadienestyrene (SBS) copolymer and atactic polypropylene polymer are most widely applied in these building elements [80]. The processing and material properties of the polymermodified bitumen membranes (PBMs) determine the functionality and bond strength with concrete, which directly influences the service life of buildings. In general, PBMs 


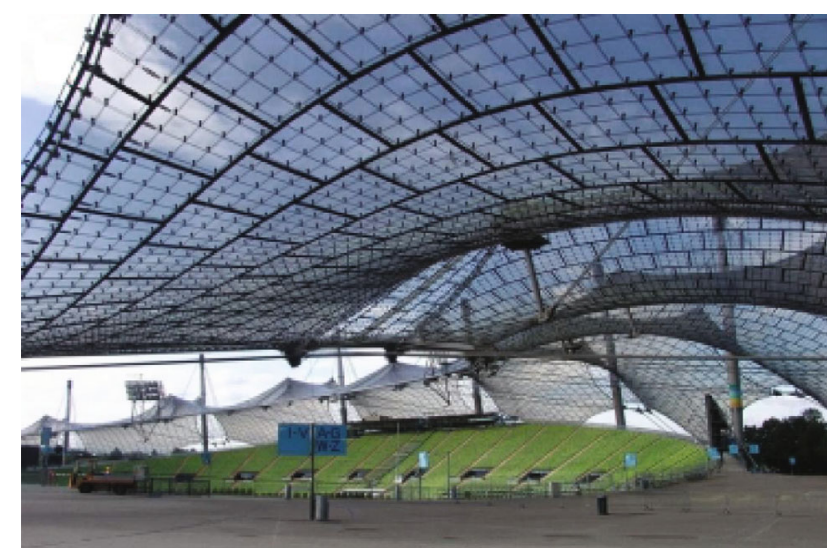

(a)

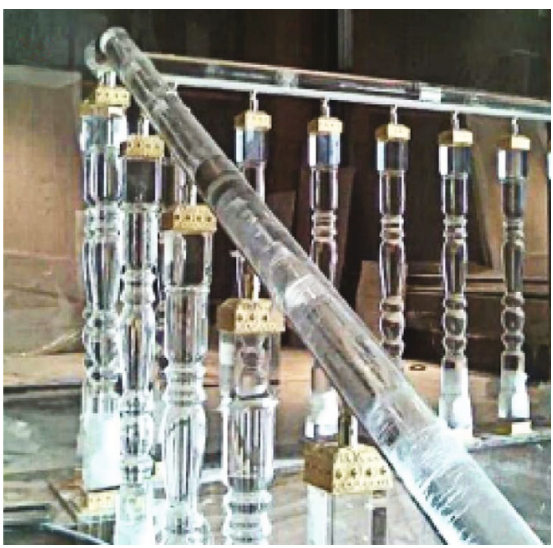

(c)

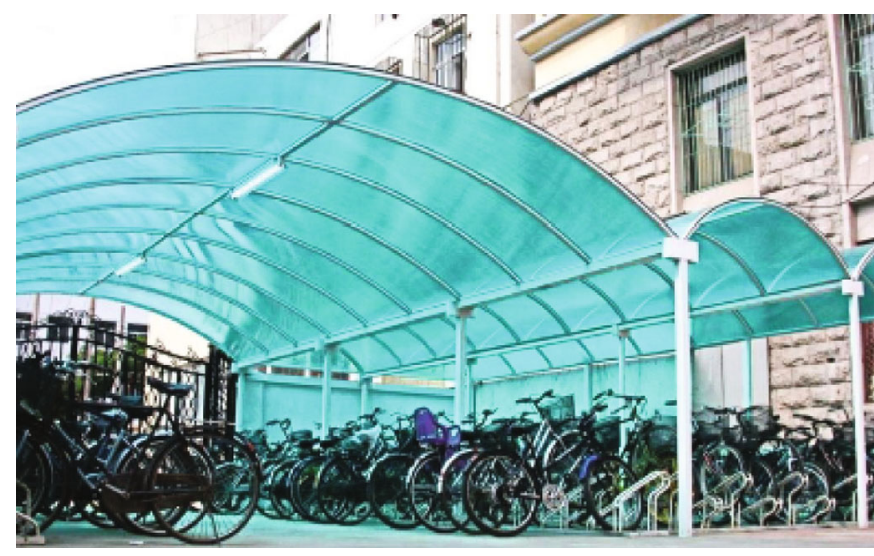

(b)

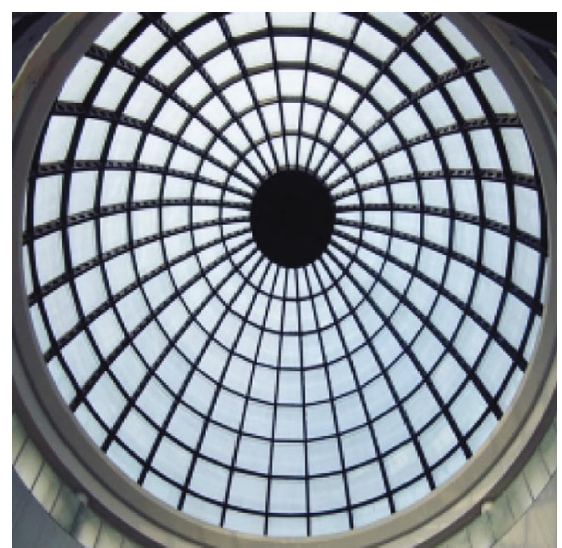

(d)

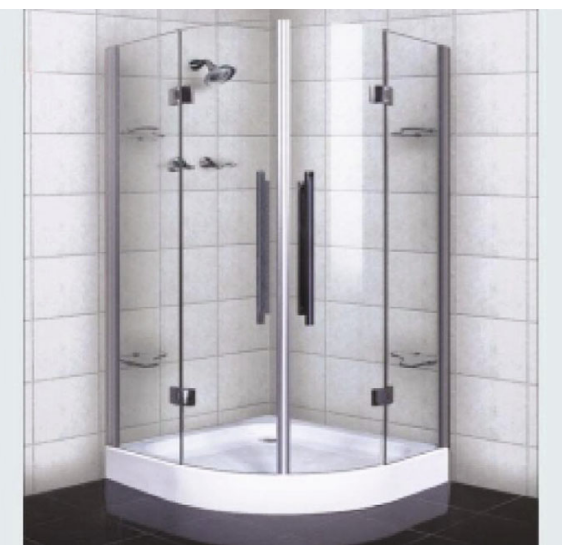

(e)

FIgURE 4: Applications of PMMA in construction and buildings. (a) Stadium for the 20th Olympic Games in Munich, Germany. (b) PMMA sun board shed. (c) Cylindrical PMMA stairs. (d) PMMA pyramid of light shade roof skylight glass. (e) Cylindrical PMMA component [71].

consist of one or two reinforcing carrier layers and two polymer-bitumen sealing materials that are coated on two sides of the carrier layers. The polymer-bitumen sealing material is a mixture of bitumen, mineral fillers, and polymers. Almost all the polymers in the polymer-bitumen sealing material are modified with an elastomer or plastomer, in which the elastomer is usually the styrene-butadienestyrene (SBS) copolymer and the plastomer is usually the atactic polypropylene polymer. When used in bridge decks, the nominal standard thickness of a waterproofing PBM is
$5 \mathrm{~mm}$. PBM is usually connected to the concrete surface with epoxy resin as a bonding agent by thermal welding using a flame or hot air.

In addition to the waterproofing of concrete bridge decks or roofs, many other building elements, including walls, facades, and cultural heritage sites, also require waterproofing. Water penetration in these building elements seriously impacts their durability. A common approach to protect these building elements is to use waterproof coatings to prevent the transport of water into the interior $[81,82]$. In 


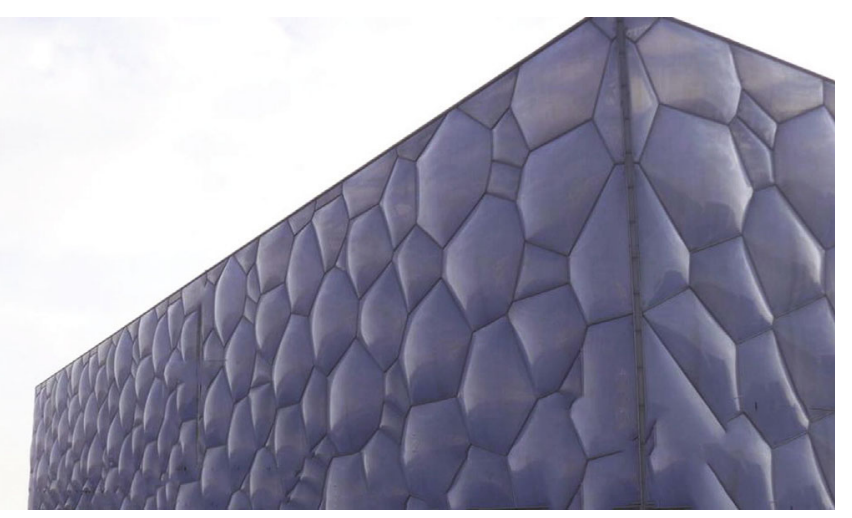

National Aquatics Center

(a)

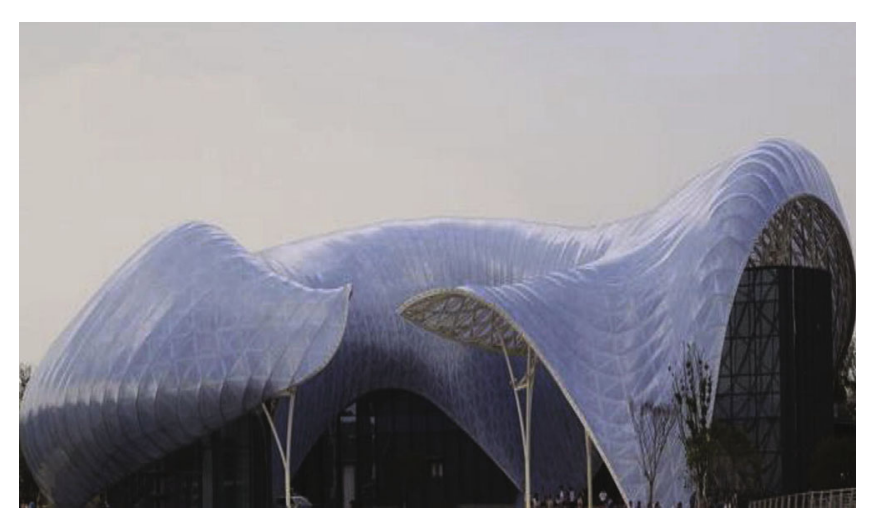

Changzhou Flora EXPO

(b)

Figure 5: Typical ETFE structures. (a) National Aquatics Center. (b) Changzhou Flora Expo [73].

addition, the application of waterproof coatings has many other properties, such as stain resistance, anti-biofouling, antisticking, anticorrosion, and self-cleaning [83-85]. The most effective and inexpensive method to prepare coatings containing these properties is the application of polymer materials fabricated with various monomers, such as acrylic, fluorinated, and silicon-based materials $[86,87]$.

Building a hydrophobic surface is a useful method for waterproof coatings [88-90]. Low surface energy and microor nanostructure of the surface are the key to the hydrophobic surface [91-93]. In the past, the polymer matrix incorporated or in situ formed with inorganic nanoparticles has been largely investigated to develop nanostructures and promote waterborne coatings [94]. The addition of inorganic nanoparticles can improve the waterproofing, mechanical, thermal, electrical, optical, or adhesive properties of the polymeric matrix, as well as some other functional properties [95-99].

Among the numerous inorganic nanoparticles used in polymer coatings, nanosilica is the most widely investigated to improve the mechanical strength, modulus, and thermal stability, as well as to enhance the water resistance of waterborne polymer coatings [100-105]. Huang et al. [106] used cellulose nanocrystals (CNCs) as a framework material to prepare a necklace-like $\mathrm{CNC} / \mathrm{SiO}_{2}$ nanostructure (referred to as the $\mathrm{CNC} / \mathrm{SiO}_{2}$ rod) via in situ growth of $\mathrm{SiO}_{2}$ as building blocks of superhydrophobic coatings (Figure 6). The $\mathrm{CNC} / \mathrm{SiO}_{2}$ rods were sprayed onto the substrates which were pretreated with adhesives, and then the $\mathrm{CNC} / \mathrm{SiO}_{2}$ superhydrophobic coatings were obtained after drying. The prepared coatings show extremely high mechanical strength under serious conditions and perform well in hydrophobicity.

Cao et al. [107] synthesized a partially fluorinated oligoadipamide (FAD) bearing pendant PFPE segments together with two diamides, i.e., ethylenediamide (DC2) and hexamethylenediamide (DC6), incorporating perfluoropolyether (PFPE) segments by condensation reactions. Using a commercial fluoroelastomer as the control, FAD displayed much better water repellence in Kerala marble samples and a similar hydrophobic effect in Lecce stone samples. Therefore, this novel oligomeric product has good potential in the protection of stone heritage.
For protecting historic buildings from graffiti writings, Lettieri et al. [108] developed a nanofilled coating based on fluorine resin with $\mathrm{SiO}_{2}$ nanoparticles and applied two products with the developed coatings on porous calcareous stones to investigate their antigraffiti ability. The developed coatings showed high hydrophobicity and oleophobicity, which totally meets the requirements for antigraffiti systems.

Except for hydrophobic coatings, there is another type of coating, namely, waterborne coating, which can prevent water transportation and is widely used in tunnel engineering and building basements. Magnesium acrylate $\left(\mathrm{CA}-\mathrm{Mg}_{2}\right)$ shot-membrane waterproofing materials are a type of hydrogel, which are commonly used in waterproof layers. Pan et al. [109] added the CA-Mg monomer into a poly(vinyl alcohol) (PVA) solution which was subjected to freezing/thawing treatment and obtained a $\mathrm{CA}-\mathrm{Mg}_{2} / \mathrm{PVA}$ interpenetrating polymer network (IPN) hydrogel. The novel IPN hydrogel contains a CA- $\mathrm{Mg}_{2}$ network generated by $\mathrm{Mg}^{2+}$ coordination bonds and a PVA network provided by hydrogen bonding between hydroxyl groups. Then, they prepared a new shotmembrane waterproofing material based on the IPN hydrogel, which could reach fracture stress of $1.44 \mathrm{MPa}$ and selfhealing efficiency of $80 \%$ at $3 \mathrm{~h}$.

Sbardella et al. [110] developed novel hybrid waterborne coatings using an acrylate copolymer with $\mathrm{SiO}_{2}$ nanoparticles and characterized them using atomic force microscopy (AFM). The addition of nanosilica created a nanoscalestructured surface and thus increased surface roughness, thereby increasing the water contact angle and creating a surface with good balance between hydrophilicity and hydrophobicity.

3.3. Others. Besides the fire-retardant coatings and waterproof coatings, there are many other functional coatings, such as heat insulation coatings [111-114], self-healing coatings [115, 116], sterilization coatings [117], icephobic coatings [118], and anticorrosive coatings [119], which are also indispensable in construction engineering.

Junior et al. [112] developed a heat-insulated polymer composite using thermoplastic starch (TPS), maleate polyethylene (PE-g-MA), and curaua fiber. The thermal capacity 


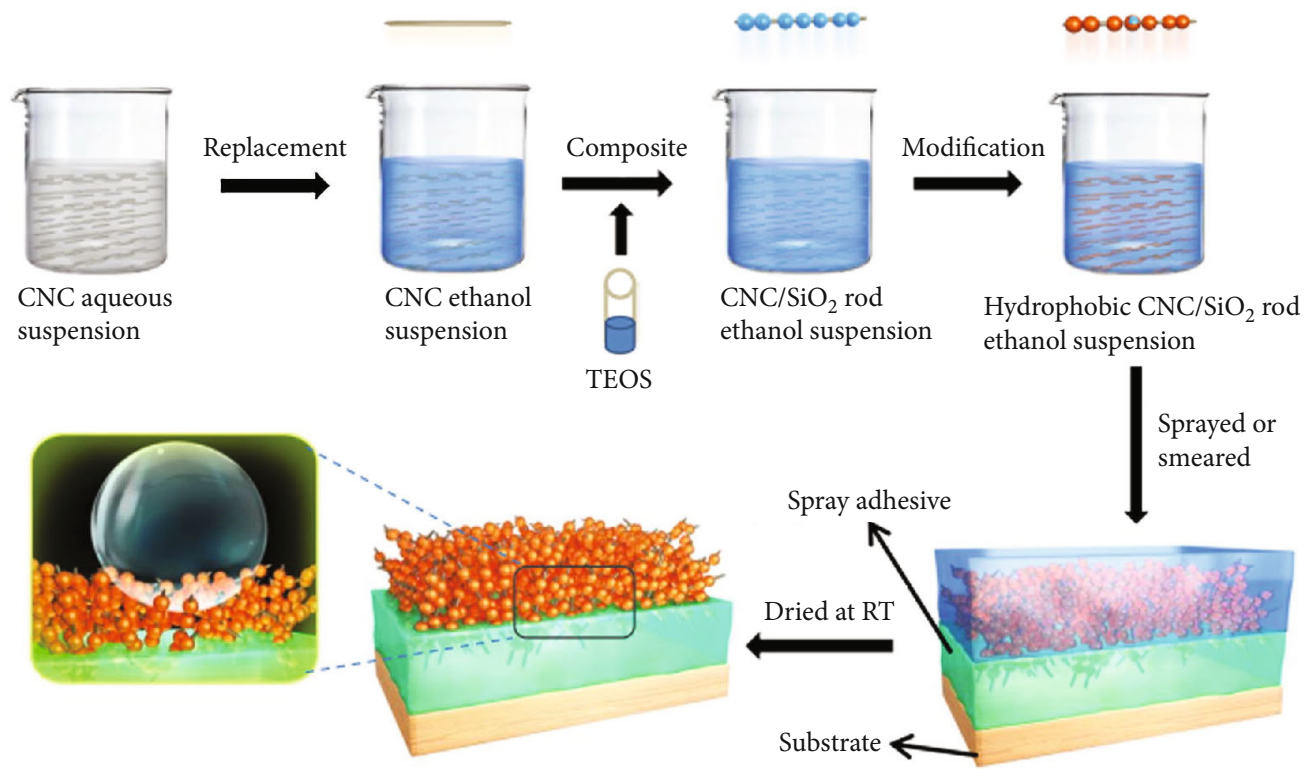

Figure 6: Schematic of preparing $\mathrm{CNC} / \mathrm{SiO}_{2}$ superhydrophobic coatings [106].

or specific heat capacity of the composite is proportional to the amount of curaua fiber. The manufactured composites have good potential to produce heat insulation coatings for construction engineering.

Nejad et al. [120] prepared a self-healing coating by infiltrating the electrospun fiber of polycaprolactone with a shape memory epoxy resin matrix by blending and polymerization-induced phase separation. After the controllable damage was applied, the self-healing ability of the coating was studied. The self-healing coating showed excellent thermal crack closure and corrosion resistance. Due to its simple process, the hybrid method is more suitable for largescale applications.

Additionally, the application of polymer coatings is accompanied by pollution of volatile organic compounds (VOCs). Common VOCs include benzene, toluene, ethylbenzene, and xylene. Martinez et al. [121] developed photocatalytic coatings for building materials using $\mathrm{TiO}_{2}$ nanoparticles incorporated in a polymer matrix-based coating. The photocatalytic coating is suitable in applications to degrade benzene, toluene, ethylbenzene, and o-m-p-xylenes.

\section{Polymer Binders}

4.1. Mortar Binders. Mortars are a series of materials that fix ceramic tiles on different substrates, mainly concrete. Cement is usually the most widely used binder material in mortars for bonding. With the development of polymer science and technology, many polymers were used to modify the cement or mortar to improve their properties. Polymers play an important role in reducing stiffness and conferring flexibility on adhesive mortars. The greater the polymer/cement ratio, the less stiff and more flexible will be the adhesive mortar. In addition, polymer performance is strongly influenced by the polymer glass transition temperature (Tg) and by the emulsifier used to produce the commercial poly- mer. Generally, the lower the Tg, the lower the Young's modulus of the mortar. Besides, the addition of polymers provides many other properties, such as workability, water retention, mechanical properties, bond strength, flexibility, and hydrophobicity $[122,123]$.

So far, the microstructure, polymer cement matrix interaction, hydration evolution, film-forming process, and mechanical performance of the polymer-modified mortars have been widely studied [124-126]. For example, Maranhao and John [127] evaluated the parameters of four commercial polymer-modified mortars in typical outdoor and indoor conditions, including mortar flexibility and bond strength with ceramic tiles. They found that the mortars have higher flexibility and bond strength in the indoor environment than in the outdoor environment.

Methylcellulose is an important constituent of adhesives and a widely used polymer for mortar modification. Pichniarczyk and Niziurska [128] carried out laboratory experiments on the effect of methylcellulose aqueous solution on the physical performance and microstructure of cementbased ceramic tile adhesives. Results of the study using the mortars with the addition of methylcellulose of various viscosities are displayed in Figure 7 . The results showed that the addition of methylcellulose in mortars greatly increases initial adhesion and prolongs open time. Besides, the higher viscosity of methylcellulose in adhesives allows obtaining a lower slip compared with lower viscosity.

Except for conventional polymer binders, biopolymers are developed as an alternative binder for soil strengthening. The biopolymer binder, as a self-sufficient local construction binder, has high potential when the use of ordinary cement is limited. Chang et al. [129] developed a microbial biopolymer and used it as an alternative binder for the construction of soil buildings. Research studies for testing the relative strength of biopolymer-mixed soils have revealed that even a little of biopolymers mixed with soil has a stronger 


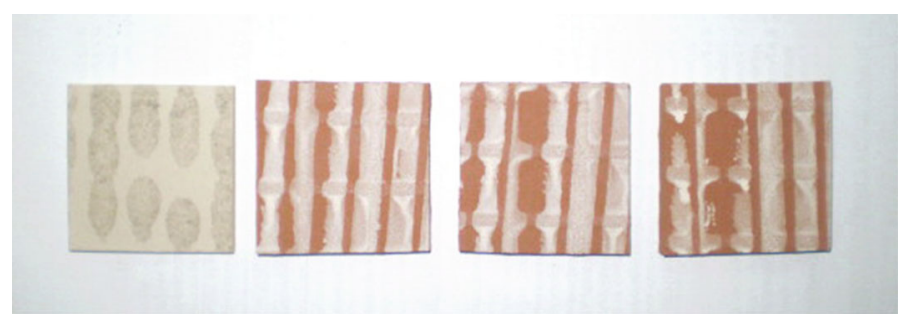

(a)
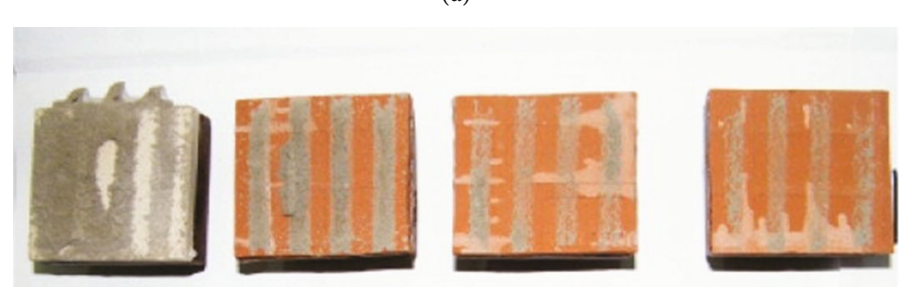

(b)
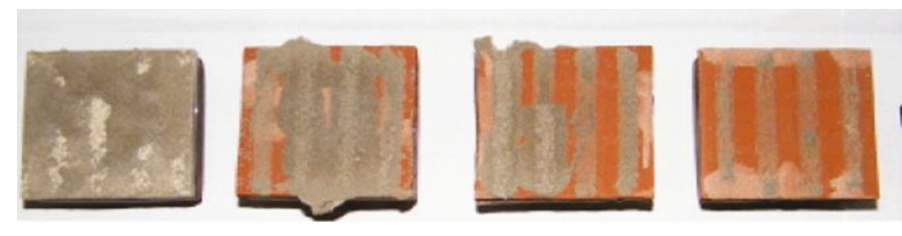

(c)

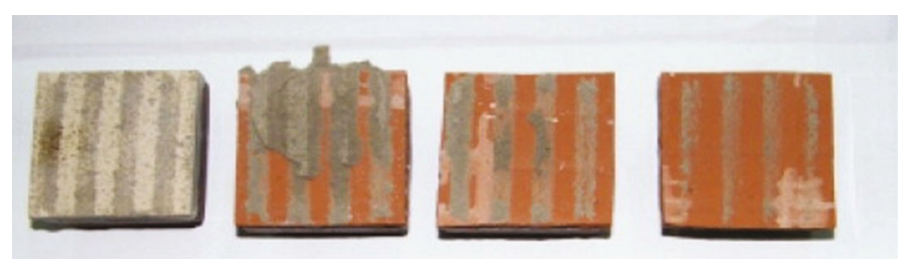

(d)

FIGURE 7: Surface of tiles from the installation site after detachment. From left: initial adhesion, open time $10 \mathrm{~min}, 20 \mathrm{~min}$, and $30 \mathrm{~min}$. Adhesives: (a) without methylcellulose, (b) with methylcellulose of 11-18 Pas viscosity, (c) with methylcellulose of 35-45 Pa s viscosity, and (d) with methylcellulose of 65-75 Pa s viscosity [128].

unconfined compression strength than soil mixed with a large amount of cement.

4.2. Asphalt Binders. Asphalt binders have been used as building materials for a long time [130]. The global consumption of asphalt binders exceeds more than 100 million tons attributed to their application in various areas [131, 132]. The development in the pavement industry, such as heavy axle design, improvement of the traffic level, heavy truckload, and environmental needs, demanded improvement of asphalt binders [133-135]. In order to adapt to the development of the pavement and construction field, people are using sustainable development technology and different types of additives and modifiers to modify the asphalt binder to improve its performance [136-141].

In recent decades, polymer modification has been used more and more in improving the high-temperature performance of asphalt pavement without reducing its lowtemperature performance [142]. However, polymer-modified asphalt may become unstable when stored at high temperatures for a long time, which will lead to degradation during production, transportation, and construction [143-146]. Chen et al. [147] modified asphalts with styrene-butadiene-styrene (SBS) and investigated the polymer concentration effect on the economy and performance of heavily trafficked highways. The results showed that the formation of SBS-modified cementitious materials is affected by storage temperature and polymer content. The formation of an interlocking continuous network can improve the rheological properties of polymermodified asphalts (PMAs). There are dramatic differences in rutting resistance and cracking resistance between highly modified asphalt mixture and normal asphalt mixture. Figure 8 shows the rut depth results with different amounts of SBS.

In recent years, the use of renewable resources derived materials (RRDM) to replace and modify asphalt binders [148-152] is also a bright spot. The vegetable- and plantderived materials have been developed as RRDM to modify asphalt binders [153-157]. Many types of RRDM, such as biochar, rice husk, palm fruit ash, and soybean flour, have been explored successfully. Tarar et al. [158] evaluated the influence of sunflower flour (SF) on rheological aspects of asphalt binders to explore whether the sunflower flour could be used as pavement and building material. Compared with 


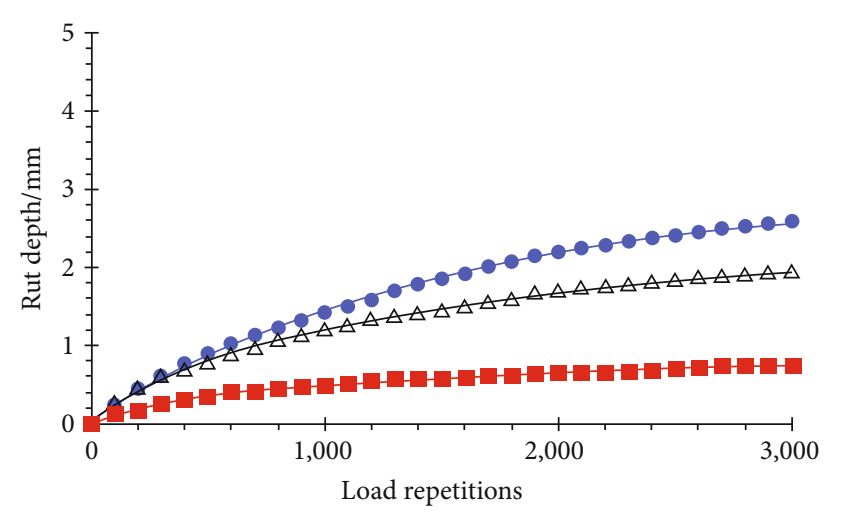

$$
\begin{array}{r}
-0 \% \text { SBS } \\
\triangle \quad 3 \% \text { SBS } \\
-6 \% \text { SBS }
\end{array}
$$

FIgURE 8: Rut depth results of laboratory specimens [147].

the unmodified adhesive, SF-modified adhesive showed higher stability at higher temperatures. The complex modulus of SFmodified asphalt cementitious materials is linear with the phase angle, which proves the stability of SF and all asphalt binders. In addition, the shear strain resistance of SFmodified cementitious materials was improved. Therefore, the SF-modified asphalt binder is a new compound which can improve the rutting performance and high-temperature performance of asphalt binders.

\section{Summary}

Polymer-based building materials have been widely used in construction engineering in recent years. By adding functional additives into these polymers or adding these polymers into traditional building materials, such as concrete and mortars, the polymer-based building materials have great advantages compared with conventional building materials. In this paper, the applications of polymer-based building materials are introduced with three classes, that is, substrates, coatings, and binders, and their recent signs of progress in the preparations and applications are carefully demonstrated.

The addition of polymers allows the concrete to obtain good mechanical strength, short curing duration, good adhesion properties, resistance to abrasion and weathering, waterproofness, and excellent insulation properties. The introduction of FRPs into prefabricated buildings is beneficial to both the structural and nonstructural components, and they have the potential to revolutionize the prefabrication building industry and to provide adequate housing for the booming population. Except for the concrete and prefabricated elements in the fields of substrates of buildings, polymer-based materials can also be used to strengthen walls or beautify the appearance of walls.

Polymer-based building coatings have been widely used for protecting the building products, beautifying the appearance, and providing special functions, such as fire-retardant coatings, waterproof coatings, heat insulation coatings, selfhealing coatings, sterilization coatings, icephobic coatings, and anticorrosive coatings. Besides, the application of polymer binders would efficiently enhance the bonding performance of mortar or cement. In some regions, polymer binders could even completely replace cement with litter performance reduction. Therefore, polymer-based building materials would have more and more wide applications in construction engineering.

\section{Data Availability}

The data used to support the findings of this study are included within the article.

\section{Conflicts of Interest}

The authors declare no conflict of interest.

\section{Authors' Contributions}

All the authors contributed to the writing of the manuscript.

\section{Acknowledgments}

This work was supported by the Scientific Research Project of the Department of Education of Zhejiang Province (Y201941709) (J.S.).

\section{References}

[1] H. Fu, H. Xu, Y. Liu et al., "Overview of injection molding technology for processing polymers and their composites," ES Materials \& Manufacturing, vol. 8, pp. 3-23, 2020.

[2] J. Sun, J. Shen, S. Chen et al., "Nanofiller reinforced biodegradable PLA/PHA composites: current status and future trends," Polymers, vol. 10, no. 5, p. 505, 2018.

[3] L. Sha, Z. Chen, Z. Chen, A. Zhang, and Z. Yang, "Polylactic acid based nanocomposites: promising safe and biodegradable materials in biomedical field," International Journal of Polymer Science, vol. 2016, 11 pages, 2016.

[4] X. Gong, L. Zhang, S. He, S. Jiang, W. Wang, and Y. Wu, "Rewritable superhydrophobic coatings fabricated using water-soluble polyvinyl alcohol," Materials \& Design, vol. 196, article 109112, 2020.

[5] L. Zhong and X. Gong, "Phase separation-induced superhydrophobic polylactic acid films," Soft Matter, vol. 15, no. 46, pp. 9500-9506, 2019.

[6] J. Xie, L. Teng, Z. Yang et al., "A polyethylenimine-linoleic acid conjugate for antisense oligonucleotide delivery," BioMed Research International, vol. 2013, Article ID 710502, 7 pages, 2013.

[7] F. Hao, Y. Li, J. Zhu et al., "Polyethylenimine-based formulations for delivery of oligonucleotides," Current Medicinal Chemistry, vol. 26, no. 13, pp. 2264-2284, 2019.

[8] S. Pan, H. Xing, X. Fu et al., "The effect of photothermal therapy on osteosarcoma with polyacrylic acid-coated gold nanorods," Dose-Response, vol. 16, no. 3, article 155932581878984, 2018.

[9] X. Gong, J. Zhang, and S. Jiang, "Ionic liquid-induced nanoporous structures of polymer films," Chemical Communications, vol. 56, no. 20, pp. 3054-3057, 2020. 
[10] H. Abdel-Fattah and M. M. el-Hawary, "Flexural behavior of polymer concrete," Construction and Building Materials, vol. 13, no. 5, pp. 253-262, 1999.

[11] M. Barbuta, R. M. Diaconescu, and M. Harja, "Using neural networks for prediction of properties of polymer concrete with fly ash," Journal of Materials in Civil Engineering, vol. 24, no. 5, pp. 523-528, 2012.

[12] M. Barbuta, M. Harja, and I. Baran, "Comparison of mechanical properties for polymer concrete with different types of filler," Journal of Materials in Civil Engineering, vol. 22, no. 7, pp. 696-701, 2010.

[13] J. P. Gorninski, D. C. Dal Molin, and C. S. Kazmierczak, "Strength degradation of polymer concrete in acidic environments," Cement and Concrete Composites, vol. 29, no. 8, pp. 637-645, 2007.

[14] B. W. Jo, S. K. Park, and D. K. Kim, "Mechanical properties of nano-MMT reinforced polymer composite and polymer concrete," Construction and Building Materials, vol. 22, no. 1, pp. 14-20, 2008.

[15] D. W. Fowler, "Polymers in concrete: a vision for the 21 st century," Cement and Concrete Composites, vol. 21, no. 5-6, pp. 449-452, 1999.

[16] J. M. L. Reis and A. J. M. Ferreira, "Assessment of fracture properties of epoxy polymer concrete reinforced with short carbon and glass fibers," Construction and Building Materials, vol. 18, no. 7, pp. 523-528, 2004.

[17] R. Giusca and V. Corobceanu, "New technologies for strengthening damaged reinforced concrete structures," Current Science, vol. 98, no. 6, pp. 829-833, 2010.

[18] O. Figovsky, D. Beilin, N. Blank, J. Potapov, and V. Chernyshev, "Development of polymer concrete with polybutadiene matrix," Cement and Concrete Composites, vol. 18, no. 6, pp. 437-444, 1996.

[19] K. S. Rebeiz, D. W. Fowler, and D. R. Paul, "Polymer concrete and polymer mortar using resins based on recycled poly(ethylene terephthalate)," Journal of Applied Polymer Science, vol. 44, no. 9, pp. 1649-1655, 1992.

[20] M. Muthukumar and D. Mohan, "Studies on furan polymer concrete," Journal of Polymer Research, vol. 12, no. 3, pp. 231-241, 2005.

[21] A. Garbacz and J. J. Sokolowska, "Concrete-like polymer composites with fly ashes - comparative study," Construction and Building Materials, vol. 38, pp. 689-699, 2013.

[22] W. Ferdous, A. Manalo, T. Aravinthan, and G. Van Erp, "Properties of epoxy polymer concrete matrix: effect of resin-to-filler ratio and determination of optimal mix for composite railway sleepers," Construction and Building Materials, vol. 124, pp. 287-300, 2016.

[23] V. Toufigh, M. Hosseinali, and S. M. Shirkhorshidi, "Experimental study and constitutive modeling of polymer concrete's behavior in compression," Construction and Building Materials, vol. 112, pp. 183-190, 2016.

[24] M. M. Shokrieh, S. Rezvani, and R. Mosalmani, "Mechanical behavior of polyester polymer concrete under low strain rate loading conditions," Polymer Testing, vol. 63, pp. 596-604, 2017.

[25] M. J. Hashemi, M. Jamshidi, and J. H. Aghdam, "Investigating fracture mechanics and flexural properties of unsaturated polyester polymer concrete (UP-PC)," Construction and Building Materials, vol. 163, pp. 767-775, 2018.
[26] A. Seco, A. M. Echeverria, S. Marcelino, B. Garcia, and S. Espuelas, "Durability of polyester polymer concretes based on metallurgical wastes for the manufacture of construction and building products," Construction and Building Materials, vol. 240, p. 117907, 2020.

[27] J. A. Rossignolo and M. V. C. Agnesini, "Durability of polymer-modified lightweight aggregate concrete," Cement and Concrete Composites, vol. 26, no. 4, pp. 375-380, 2004.

[28] M. Barbuta, N. Taranu, and M. Harja, "Wastes used in obtaining polymer composite," Environmental Engineering and Management Journal, vol. 8, no. 5, pp. 1145-1150, 2009.

[29] S. Oprea, "Effect of the diisocyanate and chain extenders on the properties of the cross-linked polyetherurethane elastomers," Journal of Materials Science, vol. 43, no. 15, pp. 5274-5281, 2008.

[30] S. Oprea and C. Ciobanu, "Effect of the temperature of polyurethane wet-casting membrane formation on the physicomechanical properties," High Performance Polymers, vol. 20, no. 2, pp. 208-220, 2007.

[31] L. Agavriloaie, S. Oprea, M. Barbuta, and F. Luca, "Characterisation of polymer concrete with epoxy polyurethane acryl matrix," Construction and Building Materials, vol. 37, pp. 190-196, 2012.

[32] Y. Kulshreshtha, E. Schlangen, H. M. Jonkers, P. J. Vardon, and L. A. van Paassen, "CoRncrete: a corn starch based building material," Construction and Building Materials, vol. 154, pp. 411-423, 2017.

[33] S. Navaratnam, T. Ngo, T. Gunawardena, and D. Henderson, "Performance review of prefabricated building systems and future research in Australia," Buildings, vol. 9, no. 2, p. 38, 2019.

[34] Q. T. Nguyen, T. Ngo, P. Tran, P. Mendis, M. Zobec, and L. Aye, "Fire performance of prefabricated modular units using organoclay/glass fibre reinforced polymer composite," Construction and Building Materials, vol. 129, pp. 204-215, 2016.

[35] Q. T. Nguyen, P. Tran, T. D. Ngo, P. A. Tran, and P. Mendis, "Experimental and computational investigations on fire resistance of GFRP composite for building façade," Composites Part B: Engineering, vol. 62, pp. 218-229, 2014.

[36] T. D. Ngo, Q. T. Nguyen, and P. Tran, "Heat release and flame propagation in prefabricated modular unit with GFRP composite facades," Building Simulation, vol. 9, no. 5, pp. 607-616, 2016.

[37] E. Guillaume, T. Fateh, R. Schillinger, R. Chiva, and S. Ukleja, "Study of fire behaviour of facade mock-ups equipped with aluminium composite material-based claddings, using intermediate-scale test method," Fire and Materials, vol. 42, no. 5, pp. 561-577, 2018.

[38] K. T. Q. Nguyen, S. Navaratnam, P. Mendis, K. Zhang, J. Barnett, and H. Wang, "Fire safety of composites in prefabricated buildings: from fibre reinforced polymer to textile reinforced concrete," Composites Part B: Engineering, vol. 187, article 107815, 2020.

[39] T. Keller, C. Haas, and T. Vallee, "Structural concept, design, and experimental verification of a glass fiber-reinforced polymer sandwich roof structure," Journal of Composites for Construction, vol. 12, no. 4, pp. 454-468, 2008.

[40] J. R. Correia, Y. Bai, and T. Keller, "A review of the fire behaviour of pultruded GFRP structural profiles for civil 
engineering applications," Composite Structures, vol. 127, pp. 267-287, 2015.

[41] M. N. S. Hadi and J. S. Yuan, "Experimental investigation of composite beams reinforced with GFRP I-beam and steel bars," Construction and Building Materials, vol. 144, pp. 462-474, 2017.

[42] M. T. Junaid, A. Elbana, S. Altoubat, and Z. Al-Sadoon, "Experimental study on the effect of matrix on the flexural behavior of beams reinforced with glass fiber reinforced polymer (GFRP) bars," Composite Structures, vol. 222, article 110930, 2019.

[43] H. Hajiloo, M. F. Green, M. Noel, N. Benichou, and M. Sultan, "Fire tests on full-scale FRP reinforced concrete slabs," Composite Structures, vol. 179, pp. 705-719, 2017.

[44] A. U. Al-saadi, T. Aravinthan, and W. Lokuge, "Structural applications of fibre reinforced polymer (FRP) composite tubes: a review of columns members," Composite Structures, vol. 204, pp. 513-524, 2018.

[45] S. Attia, S. Bilir, T. Safy, C. Struck, R. Loonen, and F. Goia, "Current trends and future challenges in the performance assessment of adaptive façade systems," Energy and Buildings, vol. 179, pp. 165-182, 2018.

[46] P. L. Nguyen, X. H. Vu, and E. Ferrier, "Thermo-mechanical performance of carbon fiber reinforced polymer (CFRP), with and without fire protection material, under combined elevated temperature and mechanical loading conditions," Composites Part B: Engineering, vol. 169, pp. 164-173, 2019.

[47] N. Simoncello, P. Zampieri, J. Gonzalez-Libreros, and C. Pellegrino, "Experimental behaviour of damaged masonry arches strengthened with steel fiber reinforced mortar (SFRM)," Composites Part B: Engineering, vol. 177, p. 107386, 2019.

[48] X. S. Lin and Y. X. Zhang, "Nonlinear finite element analyses of steel/FRP-reinforced concrete beams in fire conditions," Composite Structures, vol. 97, pp. 277-285, 2013.

[49] T. Morgado, N. Silvestre, J. R. Correia, F. A. Branco, and T. Keller, "Numerical modelling of the thermal response of pultruded GFRP tubular profiles subjected to fire," Composites Part B: Engineering, vol. 137, pp. 202-216, 2018.

[50] T. Morgado, J. R. Correia, N. Silvestre, and F. A. Branco, "Experimental study on the fire resistance of GFRP pultruded tubular beams," Composites Part B: Engineering, vol. 139, pp. 106-116, 2018.

[51] H. Ashrafi, M. Bazli, E. P. Najafabadi, and A. V. Oskouei, "The effect of mechanical and thermal properties of FRP bars on their tensile performance under elevated temperatures," Construction and Building Materials, vol. 157, pp. 10011010, 2017.

[52] V. K. R. Kodur, P. P. Bhatt, and M. Z. Naser, "High temperature properties of fiber reinforced polymers and fire insulation for fire resistance modeling of strengthened concrete structures," Composites Part B: Engineering, vol. 175, p. 107104, 2019.

[53] J. R. Correia, M. M. Gomes, J. M. Pires, and F. A. Branco, "Mechanical behaviour of pultruded glass fibre reinforced polymer composites at elevated temperature: experiments and model assessment," Composite Structures, vol. 98, pp. 303-313, 2013.

[54] Y. Bai and T. Keller, "Modeling of strength degradation for fiber-reinforced polymer composites in fire," Journal of Composite Materials, vol. 43, no. 21, pp. 2371-2385, 2009.
[55] J. G. Dai, S. Munir, and Z. Ding, "Comparative study of different cement-based inorganic pastes towards the development of FRIP strengthening technology," Journal of Composites for Construction, vol. 18, no. 3, 2014.

[56] L. Zhang, Y. Bai, Y. J. Qi, H. Fang, and B. S. Wu, "Post-fire mechanical performance of modular GFRP multicellular slabs with prefabricated fire resistant panels," Composites Part B: Engineering, vol. 143, pp. 55-67, 2018.

[57] U. Berardi and N. Dembsey, "Thermal and fire characteristics of FRP composites for architectural applications," Polymers, vol. 7, no. 11, pp. 2276-2289, 2015.

[58] E. P. Scott and J. V. Beck, "Estimation of thermal properties in epoxy matrix/carbon fiber composite materials," Journal of Composite Materials, vol. 26, no. 1, pp. 132-149, 2016.

[59] M. Adelzadeh, H. Hajiloo, and M. F. Green, "Numerical study of FRP reinforced concrete slabs at elevated temperature," Polymers, vol. 6, no. 2, pp. 408-422, 2014.

[60] T. Keller, C. Tracy, and E. Hugi, "Fire endurance of loaded and liquid-cooled GFRP slabs for construction," Composites Part A-Applied Science Manufacturing, vol. 37, no. 7, pp. 1055-1067, 2006.

[61] Y. Bai, E. Hugi, C. Ludwig, and T. Keller, "Fire performance of water-cooled GFRP columns. I: fire endurance investigation," Journal of Composites for Construction, vol. 15, no. 3, pp. 404-412, 2011.

[62] J. Ruffault, V. Moron, R. M. Trigo, and T. Curt, "Daily synoptic conditions associated with large fire occurrence in Mediterranean France: evidence for a wind-driven fire regime," International Journal of Climatology, vol. 37, no. 1, pp. 524533, 2017.

[63] W. K. Chow and J. J. E. P. Liu, "Fire hazards of façade materials for energy conservation under flashover," Energy Procedia, vol. 78, pp. 3483-3488, 2015.

[64] J. Liu and W. K. Chow, "Determination of fire load and heat release rate for high-rise residential buildings," Procedia Engineering, vol. 84, pp. 491-497, 2014.

[65] G. B. Huang, S. Q. Huo, X. D. Xu et al., "Realizing simultaneous improvements in mechanical strength, flame retardancy and smoke suppression of ABS nanocomposites from multifunctional graphene," Composites Part B: Engineering, vol. 177, article 107377, 2019.

[66] S. Ran, F. Fang, Z. Guo et al., "Synthesis of decorated graphene with $\mathrm{P}, \mathrm{N}$-containing compounds and its flame retardancy and smoke suppression effects on polylactic acid," Composites Part B: Engineering, vol. 170, pp. 41-50, 2019.

[67] N. Gattesco, I. Boem, and A. Dudine, "Diagonal compression tests on masonry walls strengthened with a GFRP mesh reinforced mortar coating," Bulletin of Earthquake Engineering, vol. 13, no. 6, pp. 1703-1726, 2015.

[68] M. Tomazevic, M. Gams, and T. Berset, "Strengthening of stone masonry walls with composite reinforced coatings," Bulletin of Earthquake Engineering, vol. 13, no. 7, pp. 20032027, 2015.

[69] N. Gattesco and I. Boem, "Characterization tests of GFRM coating as a strengthening technique for masonry buildings," Composite Structures, vol. 165, pp. 209-222, 2017.

[70] M. M. Demir, M. Memesa, P. Castignolles, and G. Wegner, "PMMA/zinc oxide nanocomposites prepared by in-situ bulk polymerization," Macromolecular Rapid Communications, vol. 27, no. 10, pp. 763-770, 2006. 
[71] S. Q. Tao, J. Fang, Y. R. Meng, H. R. Shah, and L. Z. Yang, "Ignition risk analysis of common building material cylindrical PMMA exposed to an external irradiation with in-depth absorption," Construction and Building Materials, vol. 251, article 118955, 2020.

[72] S. Robinson-Gayle, M. Kolokotroni, A. Cripps, and S. Tanno, "ETFE foil cushions in roofs and atria," Construction and Building Materials, vol. 15, no. 7, pp. 323-327, 2001.

[73] J. H. Hu, W. J. Chen, B. Zhao, and D. Q. Yang, "Buildings with ETFE foils: a review on material properties, architectural performance and structural behavior," Construction and Building Materials, vol. 131, pp. 411-422, 2017.

[74] X. Shao, Y. Du, X. Zheng et al., "Reduced fire hazards of expandable polystyrene building materials via intumescent flame-retardant coatings," Journal of Materials Science, vol. 55, no. 17, pp. 7555-7572, 2020.

[75] Z. R. Farag, J. F. Friedrich, and S. Kruger, "Cured melamine systems as thick fire-retardant layers deposited by combination of plasma technology and dip-coating," Journal of Adhesion Science and Technology, vol. 29, no. 9, pp. 807-820, 2015.

[76] S. S. Li, X. H. Lin, Z. G. Li, and X. H. Ren, "Hybrid organicinorganic hydrophobic and intumescent flame-retardant coating for cotton fabrics," Composites Communications, vol. 14, pp. 15-20, 2019.

[77] R. Otahal, D. Vesely, J. Nasadova, V. Zima, P. Nemec, and P. Kalenda, "Intumescent coatings based on an organicinorganic hybrid resin and the effect of mineral fibres on fire-resistant properties of intumescent coatings," Pigment \& Resin Technology, vol. 40, no. 4, pp. 247-253, 2011.

[78] L. Xu, X. Liu, Z. H. An, and R. Yang, "EG-based coatings for flame retardance of shape stabilized phase change materials," Polymer Degradation and Stability, vol. 161, pp. 114-120, 2019.

[79] J. A. Marques, J. G. Lopes, and J. R. Correia, "Durability of the adhesion between bituminous coatings and self-protection mineral granules of waterproofing membranes," Construction and Building Materials, vol. 25, no. 1, pp. 138-144, 2011.

[80] B. W. Hailesilassie and M. N. Partl, "Adhesive blister propagation under an orthotropic bituminous waterproofing membrane," Construction and Building Materials, vol. 48, pp. 1171-1178, 2013.

[81] A. E. Charola and C. A. Price, "Stone conservation: an overview of current research," Journal of the American Institute for Conservation, vol. 37, no. 2, p. 223, 1998.

[82] M. K. Khallaf, A. A. El-Midany, and S. E. El-Mofty, "Influence of acrylic coatings on the interfacial, physical, and mechanical properties of stone-based monuments," Progress in Organic Coating, vol. 72, no. 3, pp. 592-598, 2011.

[83] T. Kamegawa, K. Irikawa, and H. Yamashita, "Multifunctional surface designed by nanocomposite coating of polytetrafluoroethylene and $\mathrm{TiO}_{2}$ photocatalyst: self-cleaning and superhydrophobicity," Scientific Reports, vol. 7, no. 1, pp. 13628-13628, 2017.

[84] H. X. Wan, D. D. Song, X. G. Li, D. W. Zhang, J. Gao, and C. W. Du, "Failure mechanisms of the coating/metal interface in waterborne coatings: the effect of bonding," Materials, vol. 10, no. 4, p. 397, 2017.

[85] N. Wang, X. L. Diao, J. Zhang, and P. Kang, "Corrosion resistance of waterborne epoxy coatings by incorporation of dopamine treated mesoporous- $\mathrm{TiO}_{2}$ particles," Coatings, vol. 8 , no. 6 , p. 209, 2018.
[86] G. Cappelletti, P. Fermo, and M. Camiloni, "Smart hybrid coatings for natural stones conservation," Progress in Organic Coating, vol. 78, pp. 511-516, 2015.

[87] A. Calia, D. Colangiuli, M. Lettieri, and L. Matera, "A deep knowledge of the behaviour of multi-component products for stone protection by an integrated analysis approach," Progress in Organic Coating, vol. 76, no. 5, pp. 893-899, 2013.

[88] S. Naderizadeh, J. A. Heredia-Guerrero, G. Caputo et al., "Superhydrophobic coatings from beeswax-in-water emulsions with latent heat storage capability," Advanced Materials Interfaces, vol. 6, no. 5, 2019.

[89] S. L. Pagliolico, E. D. Ozzello, G. Sassi, and R. Bongiovanni, "Testing organic and organic-inorganic fluorinated hybrid coatings as protective materials for clay bricks," Journal of Coating Technology and Research, vol. 16, no. 1, pp. 81-92, 2019.

[90] H. Y. Wang, D. Y. Di, Y. M. Zhao, R. X. Yuan, and Y. J. Zhu, "A multifunctional polymer composite coating assisted with pore-forming agent: preparation, superhydrophobicity and corrosion resistance," Progress in Organic Coating, vol. 132, pp. 370-378, 2019.

[91] R. N. Wenzel, "Resistance of solid surfaces to wetting by water," Industrial and Engineering Chemistry, vol. 28, no. 8, pp. 988-994, 1936.

[92] A. B. D. Cassie and S. Baxter, "Wettability of porous surfaces," Transactions of the Faraday Society, vol. 40, pp. 546551, 1944.

[93] L. Feng, S. Li, Y. Li et al., "Super-hydrophobic surfaces: from natural to artificial," Advanced Materials, vol. 14, no. 24, pp. 1857-1860, 2002.

[94] C. E. Corcione, N. de Simone, M. L. Santarelli, and M. Frigione, "Protective properties and durability characteristics of experimental and commercial organic coatings for the preservation of porous stone," Progress in Organic Coating, vol. 103, pp. 193-203, 2017.

[95] E. K. Kim, J. Won, J. Do, S. D. Kim, and Y. S. Kang, "Effects of silica nanoparticle and GPTMS addition on TEOS-based stone consolidants," Journal of Cultural Heritage, vol. 10, no. 2, pp. 214-221, 2009.

[96] L. Dei and B. Salvadori, "Nanotechnology in cultural heritage conservation: nanometric slaked lime saves architectonic and artistic surfaces from decay," Journal of Cultural Heritage, vol. 7, no. 2, pp. 110-115, 2006.

[97] F. Xu, C. Wang, D. Li, M. Wang, F. Xu, and X. Deng, "Preparation of modified epoxy- $\mathrm{SiO}_{2}$ hybrid materials and their application in the stone protection," Progress in Organic Coating, vol. 81, pp. 58-65, 2015.

[98] J. F. Illescas and M. J. Mosquera, "Producing surfactantsynthesized nanomaterials in situ on a building substrate, without volatile organic compounds," ACS Applied Materials \& Interfaces, vol. 4, no. 8, pp. 4259-4269, 2012.

[99] S. Kugler, K. Kowalczyk, and T. Spychaj, "Influence of dielectric nanoparticles addition on electroconductivity and other properties of carbon nanotubes-based acrylic coatings," Progress in Organic Coating, vol. 92, pp. 66-72, 2016.

[100] H. Zou, S. Wu, and J. Shen, "Polymer/silica nanocomposites: preparation, characterization, properties, and applications," Chemical Reviews, vol. 108, no. 9, pp. 3893-3957, 2008.

[101] J.-Z. Ma, J. Hu, and Z.-J. Zhang, "Polyacrylate/silica nanocomposite materials prepared by sol-gel process," European Polymer Journal, vol. 43, no. 10, pp. 4169-4177, 2007. 
[102] J. L. H. Chau, C.-C. Hsieh, Y.-M. Lin, and A.-K. Li, "Preparation of transparent silica-PMMA nanocomposite hard coatings," Progress in Organic Coating, vol. 62, no. 4, pp. 436439, 2008.

[103] T. Ribeiro, C. Baleizao, and J. P. S. Farinha, "Functional films from silica/polymer nanoparticles,” Materials, vol. 7, no. 5, pp. 3881-3900, 2014.

[104] K. Zhang, L. Zheng, X. Zhang, X. Chen, and B. Yang, "SilicaPMMA core-shell and hollow nanospheres," Colloids and Surfaces A: Physicochemical and Engineering Aspects, vol. 277, no. 1-3, pp. 145-150, 2006.

[105] Y. Bao, J. Ma, X. Zhang, and C. Shi, "Recent advances in the modification of polyacrylate latexes," Journal of Materials Science, vol. 50, no. 21, pp. 6839-6863, 2015.

[106] J. D. Huang, S. Y. Lyu, Z. L. Chen, S. Q. Wang, and F. Fu, “A facile method for fabricating robust cellulose nanocrystal/$\mathrm{SiO} 2$ superhydrophobic coatings," Journal of Colloid and Interface Science, vol. 536, pp. 349-362, 2019.

[107] Y. J. Cao, A. Salvini, and M. Camaiti, "Oligoamide grafted with perfluoropolyether blocks: a potential protective coating for stone materials," Progress in Organic Coating, vol. 111, pp. 164-174, 2017.

[108] M. Lettieri, M. Masieri, M. Pipoli, A. Morelli, and M. Frigione, "Anti-graffiti behavior of oleo/hydrophobic nano-filled coatings applied on natural stone materials," Coatings, vol. 9, no. 11, p. 740, 2019.

[109] Z. Pan, Y. K. Lv, Y. L. Chen, and X. Qian, "Enhanced strength and self-healing properties of CA-Mg2/PVA IPN hydrogel used for shot-membrane waterproofing materials," Journal of Polymer Research, vol. 27, no. 5, 2020.

[110] F. Sbardella, L. Pronti, M. L. Santarelli, J. M. A. Gonzalez, and M. P. Bracciale, "Waterborne acrylate-based hybrid coatings with enhanced resistance properties on stone surfaces," Coatings, vol. 8, no. 8, p. 283, 2018.

[111] C. Barreneche, A. I. Fernandez, M. Niubo et al., "Development and characterization of new shape-stabilized phase change material (PCM)-polymer including electrical arc furnace dust (EAFD), for acoustic and thermal comfort in buildings," Energy and Buildings, vol. 61, pp. 210-214, 2013.

[112] O. G. D. Junior, R. P. de Melo, R. D. Sales, E. Ayres, and P. S. D. Patricio, "Processing and characterization of polyethylene/starch/curauá composites: potential for application as thermal insulated coating," Journal of Building Engineering, vol. 11, pp. 178-186, 2017.

[113] M. Xygkis, E. Gagaoudakis, L. Zouridi et al., "Thermochromic behavior of $\mathrm{VO}_{2}$ /polymer nanocomposites for energy saving coatings," Coatings, vol. 9, no. 3, p. 163, 2019.

[114] X. Nie, Y. Yoo, H. Hewakuruppu, J. Sullivan, A. Krishna, and J. Lee, "Cool white polymer coatings based on glass bubbles for buildings," Scientific Reports, vol. 10, no. 1, article 6661, 2020.

[115] J. Li, Q. Feng, J. Cui et al., "Self-assembled graphene oxide microcapsules in Pickering emulsions for self-healing waterborne polyurethane coatings," Composites Science and Technology, vol. 151, pp. 282-290, 2017.

[116] J. Li, Z. Li, Q. Feng et al., "Encapsulation of linseed oil in graphene oxide shells for preparation of self-healing composite coatings," Progress in Organic Coating, vol. 129, pp. 285291, 2019.

[117] T. N. Tran, A. Nourry, G. Brotons, and P. Pasetto, “Antibacterial activity of natural rubber based coatings containing a new guanidinium-monomer as active agent," Progress in Organic Coating, vol. 128, pp. 196-209, 2019.

[118] K. Zhang, X. Li, Y. Zhao et al., "UV-curable POSS-fluorinated methacrylate diblock copolymers for icephobic coatings," Progress in Organic Coating, vol. 93, pp. 87-96, 2016.

[119] N. Babaei, H. Yeganeh, and R. Gharibi, "Anticorrosive and self-healing waterborne poly(urethane-triazole) coatings made through a combination of click polymerization and cathodic electrophoretic deposition," European Polymer Journal, vol. 112, pp. 636-647, 2019.

[120] H. B. Nejad, K. L. Garrison, and P. T. Mather, "Comparative analysis of shape memory-based self-healing coatings," Journal of Polymer Science Part B: Polymer Physics, vol. 54, no. 14, pp. 1415-1426, 2016.

[121] T. Martinez, A. Bertron, G. Escadeillas, E. Ringot, and V. Simon, "BTEX abatement by photocatalytic $\mathrm{TiO}_{2}$-bearing coatings applied to cement mortars," Building and Environment, vol. 71, pp. 186-192, 2014.

[122] S. Satasivam, Y. Bai, and X. L. Zhao, "Adhesively bonded modular GFRP web-flange sandwich for building floor construction," Composite Structures, vol. 111, pp. 381-392, 2014.

[123] F. L. Maranhao, K. Loh, and V. M. John, "The influence of moisture on the deformability of cement-polymer adhesive mortar," Construction and Building Materials, vol. 25, no. 6, pp. 2948-2954, 2011.

[124] D. A. Silva, V. M. John, J. L. D. Ribeiro, and H. R. Roman, "Pore size distribution of hydrated cement pastes modified with polymers," Cement and Concrete Research, vol. 31, no. 8, pp. 1177-1184, 2001.

[125] L. Bureau, A. Alliche, P. Pilvin, and S. Pascal, "Mechanical characterization of a styrene-butadiene modified mortar," Materials Science \& Engineering, A: Structural Materials: Properties, Microstructure and Processing, vol. 308, no. 1-2, pp. 233-240, 2001.

[126] A. Jenni, R. Zurbriggen, L. Holzer, and M. Herwegh, "Changes in microstructures and physical properties of polymer-modified mortars during wet storage," Cement and Concrete Research, vol. 36, no. 1, pp. 79-90, 2006.

[127] F. L. Maranhao and V. M. John, "Bond strength and transversal deformation aging on cement-polymer adhesive mortar," Construction and Building Materials, vol. 23, no. 2, pp. 10221027, 2009.

[128] P. Pichniarczyk and M. Niziurska, "Properties of ceramic tile adhesives modified by different viscosity hydroxypropyl methylcellulose," Construction and Building Materials, vol. 77, pp. 227-232, 2015.

[129] I. Chang, M. Jeon, and G. C. Cho, "Application of microbial biopolymers as an alternative construction binder for earth buildings in underdeveloped countries," International Journal of Polymer Science, vol. 2015, Article ID 326745, 9 pages, 2015.

[130] D. Lesueur, "The colloidal structure of bitumen: consequences on the rheology and on the mechanisms of bitumen modification," Advances in Colloid and Interface Science, vol. 145, no. 1-2, pp. 42-82, 2009.

[131] A. Garcia, E. Schlangen, M. van de Ven, and G. Sierra-Beltran, "Preparation of capsules containing rejuvenators for their use in asphalt concrete," Journal of Hazardous Materials, vol. 184, no. 1-3, pp. 603-611, 2010.

[132] D. Ganter, T. Mielke, M. Maier, and D. C. Lupascu, "Bitumen rheology and the impact of rejuvenators," Construction and Building Materials, vol. 222, pp. 414-423, 2019. 
[133] G. Rusbintardjo, M. R. Hainin, and N. I. M. Yusoff, "Fundamental and rheological properties of oil palm fruit ash modified bitumen," Construction and Building Materials, vol. 49, pp. 702-711, 2013.

[134] U. Isacsson and X. Lu, "Testing and appraisal of polymer modified road bitumens-state of the art," Materials and Structures, vol. 28, no. 3, pp. 139-159, 1995.

[135] G. D. Airey, "Rheological properties of styrene butadiene styrene polymer modified road bitumens," Fuel, vol. 82, no. 14, pp. 1709-1719, 2003.

[136] X. Shu, B. Huang, and D. Vukosavljevic, "Laboratory evaluation of fatigue characteristics of recycled asphalt mixture," Construction and Building Materials, vol. 22, no. 7, pp. 1323-1330, 2008.

[137] X. Shu, B. Huang, E. D. Shrum, and X. Jia, "Laboratory evaluation of moisture susceptibility of foamed warm mix asphalt containing high percentages of RAP," Construction and Building Materials, vol. 35, no. 35, pp. 125-130, 2012.

[138] S. Zhao, B. Huang, X. Shu, X. Jia, and M. Woods, "Laboratory performance evaluation of warm-mix asphalt containing high percentages of reclaimed asphalt pavement," Transportation Research Record, vol. 2294, no. 1, pp. 98-105, 2012.

[139] S. Zhao, B. Huang, X. Shu, and M. Woods, "Comparative evaluation of warm mix asphalt containing high percentages of reclaimed asphalt pavement," Construction and Building Materials, vol. 44, pp. 92-100, 2013.

[140] M. Ghobadi, H. Jafari, G. N. Bidhendi, and A. R. Yavari, "Environmental impact assessment of petrochemical industry using fuzzy rapid impact assessment matrix," Journal of Petroleum \& Environmental Biotechnology, vol. 6, no. 6, pp. 1-7, 2015.

[141] S.-H. Yang and T. Suciptan, "Rheological behavior of Japanese cedar-based biobinder as partial replacement for bituminous binder," Construction and Building Materials, vol. 114, pp. 127-133, 2016.

[142] Y. H. Wang, D. Chong, and Y. Wen, "Quality verification of polymer-modified asphalt binder used in hot-mix asphalt pavement construction," Construction and Building Materials, vol. 150, pp. 157-166, 2017.

[143] H. Fu, L. Xie, D. Dou, L. Li, M. Yu, and S. Yao, "Storage stability and compatibility of asphalt binder modified by SBS graft copolymer," Construction and Building Materials, vol. 21, no. 7, pp. 1528-1533, 2007.

[144] B. Sengoz and G. Isikyakar, "Analysis of styrene-butadienestyrene polymer modified bitumen using fluorescent microscopy and conventional test methods," Journal of Hazardous Materials, vol. 150, no. 2, pp. 424-432, 2008.

[145] D. O. Larsen, J. L. Alessandrini, A. Bosch, and M. S. Cortizo, "Micro-structural and rheological characteristics of SBSasphalt blends during their manufacturing," Construction and Building Materials, vol. 23, no. 8, pp. 2769-2774, 2009.

[146] I. A. De Carcer, R. M. Masegosa, M. T. Vinas et al., "Storage stability of SBS/sulfur modified bitumens at high temperature: influence of bitumen composition and structure," Construction and Building Materials, vol. 52, pp. 245252, 2014.

[147] J. S. Chen, T. J. Wang, and C. T. Lee, "Evaluation of a highlymodified asphalt binder for field performance," Construction and Building Materials, vol. 171, pp. 539-545, 2018.

[148] X. Qu, Q. Liu, C. Wang, D. Wang, and M. Oeser, "Effect of co-production of renewable biomaterials on the performance of asphalt binder in macro and micro perspectives," Materials, vol. 11, no. 2, p. 244, 2018.

[149] Z. Sun, J. Yi, Y. Huang, D. Feng, and C. Guo, "Properties of asphalt binder modified by bio-oil derived from waste cooking oil," Construction and Building Materials, vol. 102, pp. 496-504, 2016.

[150] X. Yang, Z. You, Q. Dai, and J. Mills-Beale, "Mechanical performance of asphalt mixtures modified by bio-oils derived from waste wood resources," Construction and Building Materials, vol. 51, pp. 424-431, 2014.

[151] T. Rahman, M. R. Hainin, and W. A. W. A. Bakar, "Use of waste cooking oil, tire rubber powder and palm oil fuel ash in partial replacement of bitumen," Construction and Building Materials, vol. 150, pp. 95-104, 2017.

[152] G. Xu, H. Wang, and H. Zhu, "Rheological properties and anti-aging performance of asphalt binder modified with wood lignin," Construction and Building Materials, vol. 151, pp. 801-808, 2017.

[153] S. Zhao, B. Huang, X. Shu, and P. Ye, "Laboratory investigation of biochar-modified asphalt mixture," Transportation Research Record, vol. 2445, no. 1, pp. 56-63, 2014.

[154] S. Zhao, B. Huang, X. P. Ye, X. Shu, and X. Jia, "Utilizing biochar as a bio-modifier for asphalt cement: a sustainable application of bio-fuel by-product," Fuel, vol. 133, pp. 52-62, 2014.

[155] Y. Xue, S. Wu, J. Cai, M. Zhou, and J. Zha, "Effects of two biomass ashes on asphalt binder: dynamic shear rheological characteristic analysis," Construction and Building Materials, vol. 56, pp. 7-15, 2014.

[156] M. Arabani and S. A. Tahami, "Assessment of mechanical properties of rice husk ash modified asphalt mixture," Construction and Building Materials, vol. 149, pp. 350-358, 2017.

[157] R. Zhang, Q. Dai, Z. You, H. Wang, and C. Peng, "Rheological performance of bio-char modified asphalt with different particle sizes," Applied Sciences, vol. 8, no. 9, article 1665, 2018.

[158] M. A. Tarar, A. H. Khan, Z. U. Rehman, S. Qamar, and M. N. Akhtar, "Performance characteristics of asphalt binders modified with sunflower flour: a sustainable application of renewable resource derived material," Construction and Building Materials, vol. 242, article 118157, 2020. 